\title{
Analyzing spatial equality of cooling service shelters, Central district of Seoul metropolitan city, South Korea
}

\author{
Yoonjung Ahn' ${ }^{1}$ Yeora Chae $^{2}$
}

Received: 13 April 2018/Revised: 14 May 2018/Accepted: 13 July 2018/Published online: 3 August 2018

(C) The Author(s) 2018

\begin{abstract}
Frequency and intensity of extreme weather events are getting increasing. Especially heat waves occur accumulatively and the mortality rates have rapidly increased in recent years. Therefore, the government established climate change adaptation plans (CCAPs) to strengthen adaptability. However, there are various barriers that hamper implementing CCAPs and are a lack of study about reducing the barriers. Therefore, this study researched about cooling centers which is one of facilities that improving adaptability in Jung-gu, Seoul. This study evaluated the suitability of cooling centers with the adequacy of cooling centers' location and the capacity of cooling centers by comparing with the elderly population in service area. First of all, field survey was conducted. Service area and accessibility of elderly were deduced from the survey. Secondly, network analysis was done to analyze geographic suitability of cooling centers. Lastly, capacity suitability was investigated by using population in service area and compared with the capacities of each cooling centers. As a result, the service area is average $15 \mathrm{~min}$ and $20 \%$ of elderly people are living in unsuitable area for using cooling centers in Jung-gu area. Exact guideline should be suggested and more cooling center should be established to improve use of cooling center and increase adaptability.
\end{abstract}

Yoonjung Ahn

yoonjungaa@gmail.com

Yeora Chae

yrchae@kei.re.kr

1 Department of Geography, Florida State University, Tallahassee, USA

2 Korea Environment Institute, Sejong, Korea
Keywords Climate change $\cdot$ Heat waves $\cdot$ Network analysis $\cdot$ Service area

\section{Introduction}

According to the 5th report from the IPCC (Intergovernmental Panel on Climate Change), many climate change scenarios predict that the average global temperature will increase continuously. In the Representative Concentration Pathway (RCP) 8.5, it is predicted that the average global temperature will increase by $2.6-4.9^{\circ} \mathrm{C}$, and a heat wave will last more often and longer with a very high probability.

In 2016, an unprecedented heat wave phenomenon was observed around the globe. In India, the highest temperature in April was exceeded by $4.85^{\circ} \mathrm{C}$, and temperature over $40{ }^{\circ} \mathrm{C}$ persisted for 17 days in the southwestern part of the United States. Temperature of 51 and $47{ }^{\circ} \mathrm{C}$ was recorded in Iraq and Egypt, respectively, creating 447 patients suffering from heatstroke [1]. Heat waves affect throughout the world, and the rate of increase in the death toll during 2001-2010 was $2300 \%$, showing a higher rate of increase than the rate of increase in the death toll due to other weather conditions such as flood, typhoon, drought and intense cold, it is therefore recognized as a disaster [2]. In Korea, the number of patients suffering from heat-related diseases ${ }^{1}$ clearly shows a growing trend since 2002, and the number of patients suffering from heat-related diseases increased by 4 times in case of outpatients and by 16 times in case of inpatients in 2016 compared to those in 2002 [3]. ${ }^{2}$

\footnotetext{
${ }^{1}$ Level 9 Disease code T67-type heat-related diseases including sunstroke and heatstroke.

${ }^{2}$ Homepage of National Health Insurance Service (https://www.nhis. or.kr/retrieveHomeMain.xx Accessed: 2017. 11. 16).
} 
Because of the increased negative effects of heat wave, the importance of adaptation is being emphasized in international societies, and it was decided to consider both reduction and adaptation in Intended Nationally Determined Contributions (INDCs) of the Paris Agreement (Post-2020) which is the follow-up measure of Kyoto Protocol. Accordingly, major foreign countries (England, Japan, and the US) have established the climate change adaptation measures, and our country has established and is implementing climate change adaptation measures and detailed execution plans at the national, metropolitan and local government level.

The vulnerable assessment and risk assessment are widely used for establishing a scientific climate change adaptation measure, and these methods have an advantage that political priorities can be set. However, the indices [4-7] of number or availability of resources (number of public officials, availability of facility, number of facilities) utilized for evaluation cannot evaluate whether such resources actually contribute to the improvement of adaptability or the possibility to utilize such resources $[8,9]$. Therefore, it is necessary to examine the availability of resources or properties as well as actual possibility to use and utilize in order to increase the ability to adapt a climate change.

Actual possibility to use resources has been evaluated through effectiveness, efficiency and equity. Effectiveness is defined as the satisfaction level in service [10], efficiency means the maximum output compared to input [11], and equity means benefits of public service are equally provided to people without any underprivileged people [12]. Equity is an element to measure fair distribution of resources such as accessibility, and the appropriateness of resource distribution has been evaluated through the analysis of service area and traveling time. In foreign countries, many studies to evaluate the possibility to use of installed facilities for reducing climate change effect have been conducted based on service areas [13-15]. Multiple studies to evaluate the possibility to use of service facilities based on service areas have also been performed in the country [16-20], but the target facilities are mainly welfare facilities, health facilities, evacuation facilities, disaster prevention facilities, educational facilities and leisure facilities. Therefore, the evaluation of equity of climate change adaptation facilities has not been conducted properly. Also, many analyses on the location equity of relevant facilities were mainly based on service zones and traveling time [16-19], so there is a lack of study considering the number of persons that can be accommodated by service facility.

Therefore, the purpose of this study is to investigate the operating status of domestic and foreign cooling service shelters installed and designated as heat wave adaptation facilities, and evaluate the equity of such facilities by considering accommodation capacity and service area of cooling service shelters.

\section{Study area, materials and methods}

The spatial range of this study is cooling service shelters in Jung-gu, Seoul Metropolitan City. Cooling service shelter is a facility installed for senior citizens and people having mobility difficulties or physical weakness who are vulnerable to heat waves, and it is installed in centers for senior citizens, community halls, community centers, banks, libraries and welfare centers. Such shelters were drawn based on damaged areas and urban areas with high temperature (number of days with a temperature over $33{ }^{\circ} \mathrm{C}$ ) for the past 10 years with reference to the disaster vulnerability analysis [21] presented in Ministry of Land, Infrastructure, and Transport's Guideline No. 707 "Guideline on the analysis and utilization of vulnerability to urban climate change disaster". Considering the fact that cooling service shelter was installed for the elderly (over 65 years old), an area with high density of population over 65 years old was selected as a potentially vulnerable area (Table 1).

A weight for each index was not given for analyzing a vulnerable area, and the standardized equation using mean and standard deviation that were less influenced by the minimum value and maximum value of each variable among the standardization methods was utilized. An area with relatively large sum of standardized value of vulnerable environment variable and vulnerable citizen index was drawn as a potentially vulnerable area. As a result of analyzing a potentially vulnerable area, Jung-gu included 5 dongs among top 5\% vulnerable areas (25 Gus and 423 administrative dongs) in Seoul Metropolitan City, so Junggu district was selected as a potentially vulnerable area. 26 cooling service shelters are designated in Jung-gu district and these shelters can accommodate 966 people $^{3}$ which take approximately $11 \%$ of the population over 65 years old in Jung-gu district [22].

\subsection{Use and distribution status of cooling service shelters}

First, operation status and problems of cooling service shelter were determined through field investigation and survey. The survey was carried out on July 14, 2016, and 6 places ('Yangjitmal senior community center', 'Pil-dong senior community center', 'Saemal senior community

\footnotetext{
${ }^{3}$ Internal data of Ministry of Public Administration and Security regarding cooling service shelters (2016).
} 
Table 1 Heatwave vulnerability assessment indices

\begin{tabular}{|c|c|c|c|c|}
\hline Category & Sub category & Data & References & Data source \\
\hline \multirow[t]{2}{*}{ Vulnerable environment } & Climate & $\begin{array}{l}\text { Number of days maximum } \\
\text { temperature above } 33 \text { degrees }\end{array}$ & {$[14,20,21]$} & The Meteorological Administration \\
\hline & Potential vulnerable area & Number of extreme heat mortality & {$[20]$} & National Statistical Office \\
\hline Vulnerable citizen & Personal attributes & Elderly population density & {$[4,20,21]$} & $\begin{array}{l}\text { National Spatial } \\
\text { Information Clearinghouse }\end{array}$ \\
\hline
\end{tabular}

center', 'Geumho 3-ga senior community center', 'Huamdong Community Service Center' and 'Geumho 2, 3-ga dong Community Service Center') were selected in order to equally visit an area with many cooling service shelters and an area lacking cooling service shelters in Jung-gu, Seoul.

The survey was conducted targeting 6 relevant officials and 30 cooling service shelter users. Upon performing the survey, explanation on each question was provided to help the understanding of survey contents, and if a respondent was unable to read, survey contents were read to the respondent, allowing him/her to answer.

\subsection{Equity analysis of cooling service shelter}

The traveling distance which was widely used in precedent studies was considered for the evaluation of equity of resources, considering the fact that accommodation capacity of cooling service shelter was an important element for the use of facility [23], equity analysis was conducted by considering the ratio of number of people in service area to accessibility and number of persons that could be accommodated.

In order to analyze the equity of cooling service shelters, population data, political map data, side walk data, and cooling center location data were used (Table 2). The equity of service area was analyzed using facility location analysis method considering service area which is one of the GIS network analysis methods (location-distribution model). Service zones were drawn based on the average traveling time of respondents and accessibility of domestic and overseas shelters and health centers derived from survey contents [13-15] (Tables 3, 5). The walking speed of the elderly (approximately $0.73 \mathrm{~m} / \mathrm{s}$ ) was considered for drawing the service areas [15, 24-26].

Lastly, the ratio of number of people available for accommodation to the number of population in the service zone was drawn in consideration of the fact that accessibility as well as the number of people to be accommodated was important factors for actual utilization of cooling service shelter [27, 28]. Ranking of equity of cooling service shelter was drawn by giving weight according to the accessibility [12] (Eq. 1)
$\left(X_{i} / P 15_{i}\right) * 100 * 2+\left(X_{i} / P 25_{i}\right)$

$X_{i}=E /$ number of persons that can be accommodated in $i$ th cooling service shelter, $P 15_{i}=$ Number of population over 60 years old in an area within 15 min from ith cooling service shelter, $P 25_{i}=$ Number of population over 60 years old in an area within $25 \mathrm{~min}$ from $i$ th cooling service shelter.

\section{Result and discussion}

\subsection{Analysis result of use and distribution status of cooling service shelters}

Cooling service shelters in Jung-gu, Seoul Metropolitan City were distributed mainly in Euljiro-dong, Hwanghakdong, Sindang 5-dong, Sindang 6-dong, Sindang 3-dong, Hoehyeon-dong and Jungnim-dong, and the number of cooling service shelter in Sogong-dong, Pil-dong, Myeongdong, Sindang 2-dong, Jangchung-dong, Gwanghui-dong and Sindang 1-dong was 0 (Fig. 1).

The cooling service shelter is installed mainly in facilities including centers for senior citizens, community halls, community centers and welfare centers, and it is operated by the disaster management department of autonomous district. Each cooling service shelter is managed and operated by one designated administrator (president). The operating expense of cooling service shelter is supported by the government subsidies, and in case of senior community center-type cooling service shelter, membership fee (25,000 KRW $\sim 40,000 \mathrm{KRW}$ per year) is collected additionally. A management official from a cooling service shelter explained that a large number of people visit senior community center-type cooling service shelter mostly during lunch hours because lunch was served (Table 4). Senior community center-type cooling service shelter is equipped with a rest place, but community service-type cooling service shelter has no separate rest space. Thus, it is judged to have less function as a rest area.

According to the 'cooling service shelter designation, operation and management guideline', it is required to secure the space of $4 \mathrm{~m}^{2}$ or more per person considering the number of target users. It is recommended to secure 
Table 2 Data Source

\begin{tabular}{lll}
\hline Data & Format & Source \\
\hline Population data & Point & Biz gis \\
Political map & Polygon & Ministry of Public Administration and Security \\
Side walk & Line & Ministry of Public Administration and Security \\
Cooling center locations & Point & Ministry of Public Administration and Security \\
\hline
\end{tabular}

Table 3 Service area references

\begin{tabular}{lll}
\hline Facilities & Standard & References \\
\hline Emergency shelter & Within $1 \mathrm{~km}$ & {$[14]$} \\
& Within 30 min by feet & {$[15]$} \\
Health care center & $20-30$ min by feet & {$[13]$} \\
Cooling center & 15 min by feet & {$[26]$} \\
\hline
\end{tabular}

separate space for a disaster helper for education and promotion purposes. However, in case of community service center, it is identified that the space for administration service is called as cooling service shelter. It is also confirmed that senior community center-type cooling service shelter is operated based on members of senior community center, so there is a limitation for a non-member to use the place. The fact that there is no separate rest space in the community service center brings a limitation in psychological accessibility. Existing limitation for a non-member to use senior community center were mentioned as a problem in precedent studies [24], it is judged that this matter should be considered in future for establishing a cooling service shelter.

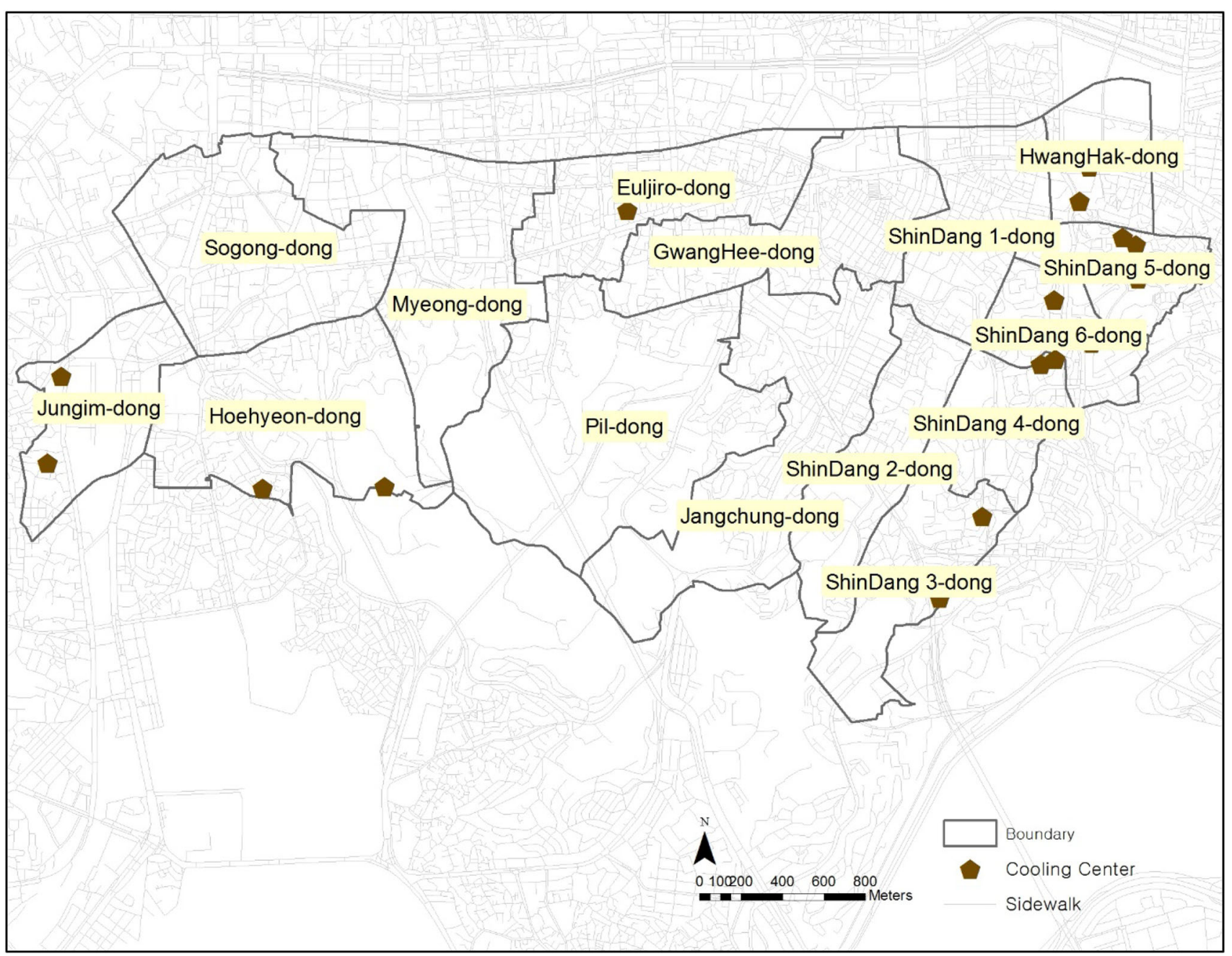

Fig. 1 Location of cooling centers 
Table 4 Interview results about cooling center management and use

\begin{tabular}{lllllll}
\hline Categories & 1 & 2 & 3 & 4 & 5 & 6 \\
\hline Manager & 0 & $\bigcirc$ & $\bigcirc$ & 0 & 0 & 0 \\
Total number of members & 115 & 70 & 80 & 11 & - & - \\
The number of visitors per day & 20 & 10 & 40 & 6 & - & - \\
Peak time & 11 am-13 pm & 12 pm-17 pm & $11 \mathrm{am}-12 \mathrm{pm}$ & $12 \mathrm{pm}-14 \mathrm{pm}$ & - & - \\
Advertisement & $\mathrm{X}$ & $\mathrm{X}$ & $\mathrm{X}$ & $\mathrm{X}$ & $\mathrm{X}$ & $\mathrm{X}$ \\
\hline
\end{tabular}

1 Yanginmal senior community center, 2 Saemal senior community center, 3 Pildong senior community center, 4 Geumho 3 ga senior community center, 5 Huamdong community service, 6 Geumho $2 \cdot 3$ gadong service

\subsection{Equity analysis result of cooling service shelter}

The service area within $660 \mathrm{~m}$ and within $1100 \mathrm{~m}$ that required $15-25$ min by walk based on the walking speed of the elderly was selected by referring to precedent studies and survey contents (Tables 3,4).

As a result of analyzing service areas, the number of cooling service shelters which are accessible within
15-25 min by walk in Sogong-dong and Myeong-dong (A area), Gwanghui-dong (B area) and Pil-dong (C area) was insufficient (Fig. 2). The number of population that have access to cooling service shelter within 15 and 25 min was approximately $17,900 \quad(31 \%$ of the population over 60 years old) and 39,700 (69\% of the population over 60 years old), respectively (Table 5).

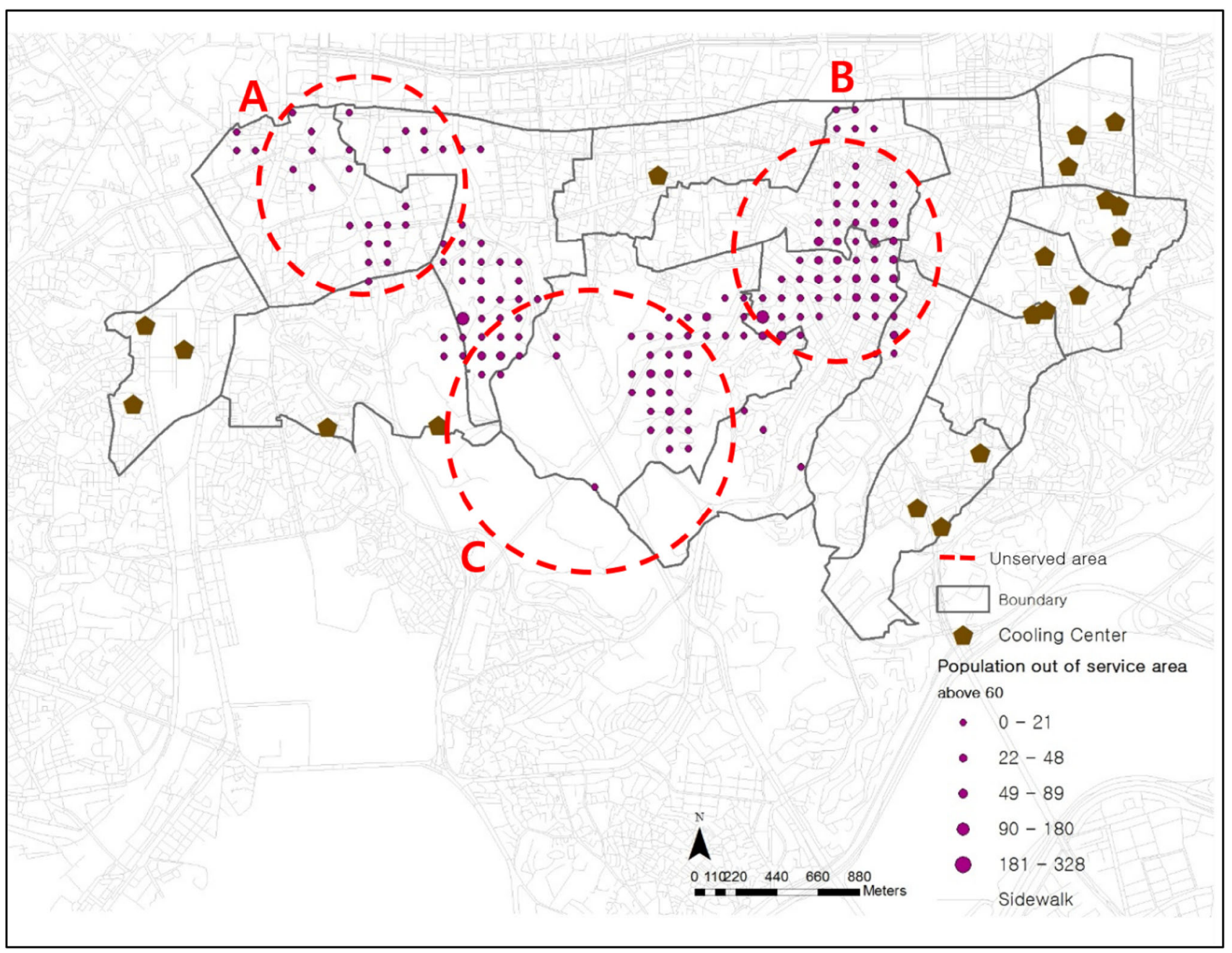

Fig. 2 Cooling center suitability analysis based on service area and capacity. A: Sogong dong and Myeongdon area, B: Gwanghee dong, C: Pildong dong 
Table 5 Questionnaires and responses about cooling center use

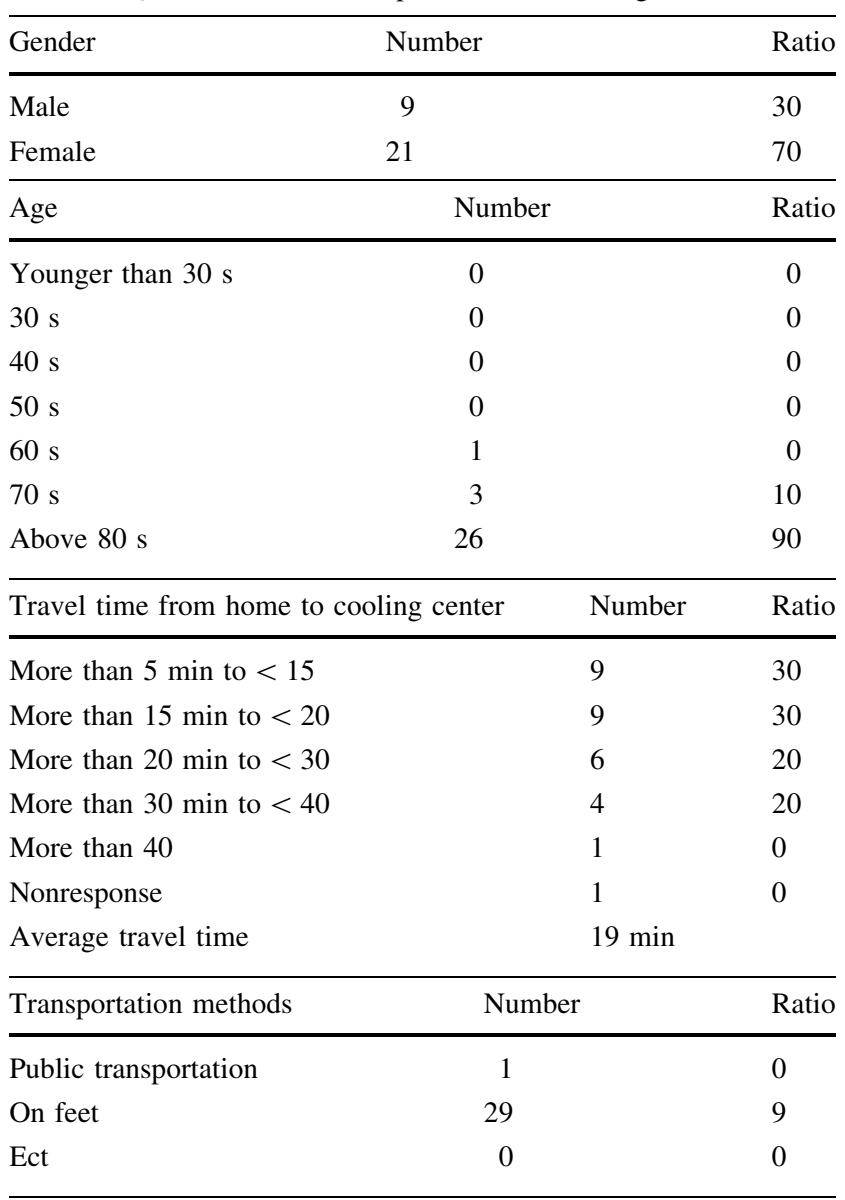

The number of persons to be accommodated by each location and the number of population in the service zone (Table 6, Fig. 3) was derived, and ratio of the number of persons to be accommodated by cooling service shelter to the number of population in each service zone was examined in order to analyze the appropriateness of location of cooling service shelter. As a result of drawing the equity rank by giving a weight of $2: 1$ to the ratio of population in an area that is accessible within $15 \mathrm{~min}$ and the ratio of population in an area that is accessible within $25 \mathrm{~min}$, Cheongpa Welfare Center for the Elderly was selected as the first priority since the number of persons to be accommodated in the service area to the number of persons to be accommodated by cooling service shelter was the largest, followed by Saemal senior community center as the second priority and Kukdong Miraju APT senior community center as the third priority. The number of persons to be accommodated by Cheongpa Welfare Center for the Elderly which was ranked top for the equity was 150 people and it was most suitable as the facility with the largest number of persons to be accommodated. On the other hand, in case of Kukdong Miraju APT senior community center and Geumho Xi 1st APT senior community center, the number of persons to be accommodated was less but the number of potential users in an area within 15 and 25 min by walk was smaller than the number of persons to be accommodated by cooling service shelter, therefore, these facilities were considered as suitable cooling service shelters.

In case of Geumho Community Credit Cooperative (headquarter) and Nongol Credit Union, the number of persons to be accommodated was less, but considering the fact that the number of population over 60 years old within the service area was large, it is judged that establishing additional cooling service shelter in their surrounding areas should be considered. The number of population over 60 years old with no accessible cooling service shelter within 15 and $25 \mathrm{~min}$ is 388 people in Sindang 3-dong, 1442 people in Sindang 2-dong, 731 people in Pil-dong, 755 people in Jangchung-dong, 50 people in Sindang 4-dong, 346 people in Myeong-dong, 394 people in Hoehyeon-dong, 136 people in Sogong-dong, 772 people in Sindang 1-dong, 753 people in Gwanghui-dong and 86 people in Euljiro-dong, indicating that it is necessary to designate an additional cooling service shelter to an accessible place for a total of 5857 people. Also, it is judged that the designation or installation of cooling service shelter should be considered by priority for Sogongdong, Pil-dong, Myeong-dong, Sindang 2-dong, Jangchung-dong, Gwanghui-dong and Sindang 1-dong where no cooling service shelter exists.

The analysis result shows that there is no cooling service shelter in 7 out of 15 dongs of Jung-gu, Seoul Metropolitan City (Fig. 1). Cheongpa Welfare Center for the Elderly showing the highest equity of each cooling service shelter can accommodate only $62 \%$ of potential people to be accommodated in an area within $15 \mathrm{~min}$ and $19 \%$ of those in an area within $25 \mathrm{~min}$ (Table 5). In consideration of this fact, it is considered that the number and accommodation capacity of cooling service shelters in Jung-gu, Seoul Metropolitan City are insufficient. In foreign countries, type of cooling service shelter is classified into public spaces (library, swimming pool), hospitals and clinics and commercial facilities (department stores, shopping centers, supermarkets, etc.) [29], and public spaces are actively utilized as cooling service shelter. In our country, it is also necessary to examine a measure to expand cooling service shelter to various public spaces in addition to senior community centers, welfare facilities and community service centers. 
Table 6 Result of suitability analysis

\begin{tabular}{|c|c|c|c|c|c|}
\hline Cooling center & Capacity & $\begin{array}{l}\text { Population within } \\
15 \mathrm{~min}(660 \mathrm{~m})(\%)\end{array}$ & $\begin{array}{l}\text { Population within } \\
25 \mathrm{~min}(1100 \mathrm{~m})(\%)\end{array}$ & Suitability & Rank \\
\hline Cheongpa welfare center for the elderly & 150 & $487.76(62)$ & $794.75(19)$ & 0.803795 & 1 \\
\hline Saemal senior community center & 50 & $255.71(39)$ & $377.51(13)$ & 0.523515 & 2 \\
\hline Kukdong Miraju Apt senior community center & 20 & $126.1(32)$ & $124.96(16)$ & 0.47726 & 3 \\
\hline Sindang 5dong senior community center & 29 & $130.65(44)$ & $2206.23(1)$ & 0.457079 & 4 \\
\hline Kumho 1 Cha Apt & 25 & $316.34(16)$ & $352.9(7)$ & 0.228899 & 5 \\
\hline Geumho 1ga community service & 40 & $603.09(13)$ & $765.07(5)$ & 0.184933 & 6 \\
\hline Pildong senior community center & 53 & $1010.33(10)$ & $1629.31(3)$ & 0.137445 & 7 \\
\hline Yanginmal senior community center & 85 & $1545.04(11)$ & $3675.84(2)$ & 0.133153 & 8 \\
\hline Seogye senior community center & 70 & $1906.34(7)$ & $4044.58(2)$ & 0.090746 & 9 \\
\hline Kookmin Bank Oksu & 15 & $478.13(6)$ & $561.1(3)$ & 0.089478 & 10 \\
\hline
\end{tabular}

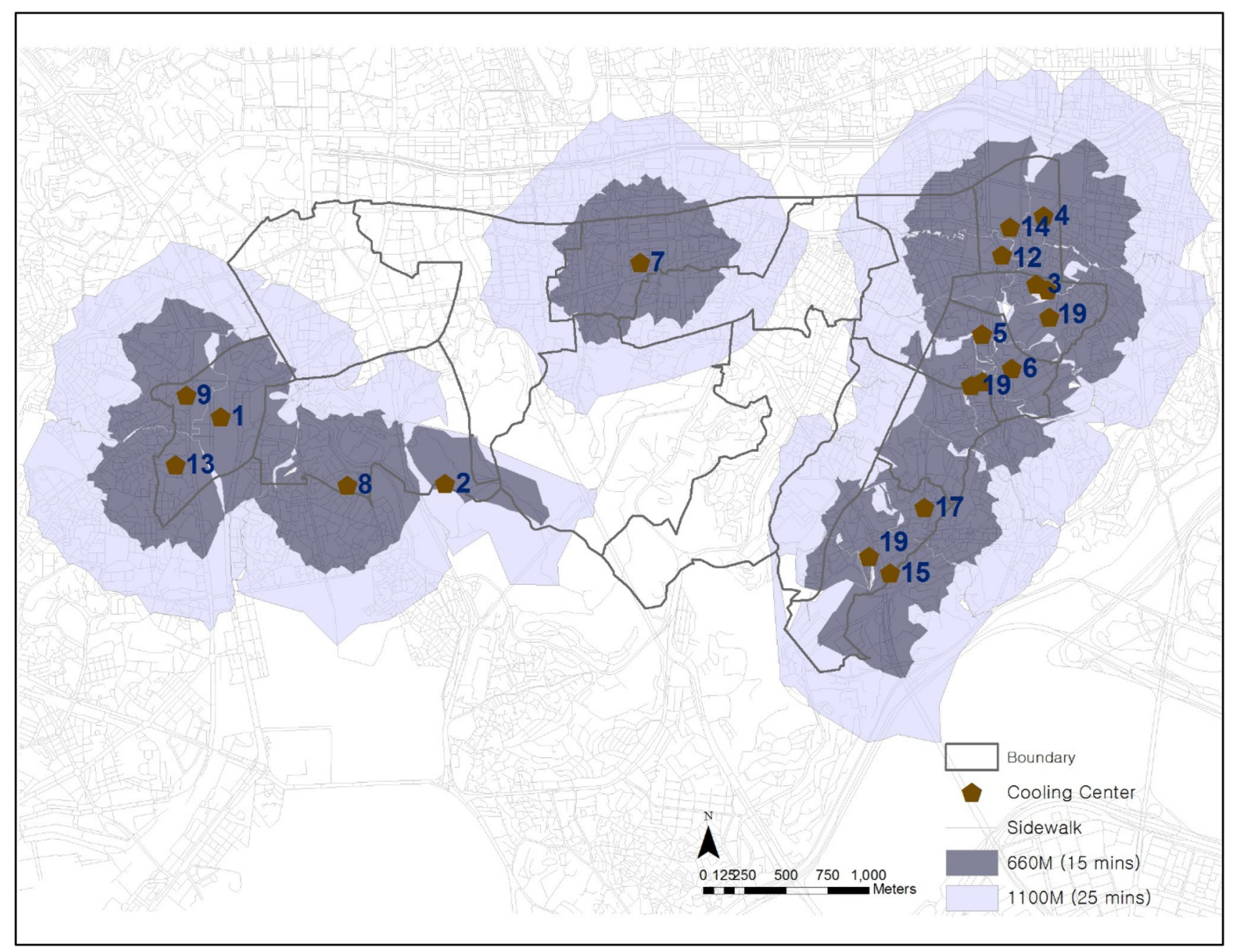

Fig. 3 Result of suitability analysis. Numbers represent suitability of cooling center (lower number is more suitable cooling center) 


\section{Conclusion}

In this study, operating status of cooling service shelters and standard of service area were drawn through a field investigation and a survey, and the equity of cooling service shelter installation was analyzed through the accessibility and number of population to be accommodated. The result of status analysis showed that the definition of cooling service shelter was vague and there was a limitation in using such facility due to its unclear installation standard.

Also, cooling service shelters were mainly used by senior citizens over 80 years old and the traveling time to a cooling service shelter ranged between approximately 5 and $40 \mathrm{~min}$, having an average traveling time of $15 \mathrm{~min}$. In consideration of such fact, it is necessary to install a cooling service shelter in a location that is accessible within 15 min on average from an area vulnerable to a heat wave in future.

Analysis result of service areas drawn through survey and literature search showed that the area of Sogong-dong, Myeong-dong, Gwanghui-dong and Pil-dong were not suitable to use a cooling service shelter within 15-25 min by walk. The number of population in unsuitable areas was approximately 3000 people, accounting for approximately $20 \%$ of total population of older people in Jung-gu district. It is necessary to prepare a countermeasure for a heat wave in order to supplement insufficient cooling service shelter facilities by designating additional cooling service shelters that can accommodate these people or providing door-todoor medical service.

This study has its significance that the status of cooling service shelters operated by government institutions was analyzed and the equity of facility installation was examined, in order to improve the adaptability on heat wave. It is judged that the result of this study could be utilized as preliminary data for installing and establishing a cooling service shelter efficiently in future.

There is a limitation in this study that the possibility to move between administrative districts was not considered since the analysis was performed with administrative district as a unit for political support. Moreover, target area was limited to Jung-gu district, so it is insufficient to generalize the result of this study. It is necessary to conduct studies on selecting proper location for additional cooling service shelters, understanding the status of cooling service shelters across the country and its installation in future.

Acknowledgements This work was funded by the Korea Meteorological Administration Research and Development Program under Grant KMI(KMI2018-01410).

Open Access This article is distributed under the terms of the Creative Commons Attribution 4.0 International License (http:// creativecommons.org/licenses/by/4.0/), which permits unrestricted use, distribution, and reproduction in any medium, provided you give appropriate credit to the original author(s) and the source, provide a link to the Creative Commons license, and indicate if changes were made.

\section{References}

1. National Emergency Management Agency. (2016). Annual Report of Disaster.

2. Benali, A., Carvalho, A. C., Nunes, J. P., Carvalhais, N., \& Santos, A. (2012). Estimating air surface temperature in Portugal using MODIS LST data. Remote Sensing of Environment, 124, 108-121.

3. National Health insurance Serivce. (2017). www.nhis.or.kr. Accessed 07 November 2017.

4. Yoo, G. Y., \& Kim, I. E. (2008). Development and application of a climate change vulnerability index. Sejong: Korea Environment Institute.

5. Lee, M.-H., Jung, I.-W., \& Bae, D.-H. (2011). Korean flood vulnerability assessment on climate change. Korea Water Resource Association, 44(8), 653-666.

6. Lee, D.-K. (2011). Developing methodology for climate change vulnerable assessment. Incheon: National Institute of Environment Research.

7. National Institute of Environmental Research. (2012). Establishing climate change adaptation plans for local.

8. Chae, Y. R. (2016). Developing climate change combat capability assessment framework. Sejong: Korean Environment Institute.

9. Hong, J., Lim, H. J., Ham, Y. H., \& Lee, B. J. (2015). Grid unit based analysis of climate change driven disaster vulnerability in urban area. The Korean Association of Geographic Information Studies, 23(6), 67-75.

10. Lee, H. T. (2003). A study on the analysis of citizen satisfaction for urban public service. The Korean Journal of Local Government Studies, 7(4), 215-232.

11. Jo, J. H. (2016). Analysis of efficiency influence factor of public services: Focused on comprehensive social welfare center. The Korean Journal of Local Government Studies, 20(1), 189-220.

12. Lee, G. J., \& Lm, E. S. (2009). Developing a methodological framework for assessing the level of neighborhood park service provision. Korea Planning Association, 63, 107-122.

13. Kar, Bandana, \& Hodgson, Michael E. (2008). A GIS-based model to determine site suitability of emergency evacuation shelters. Transactions in GIS, 12(2), 227-248.

14. Kwapong, Nana Afranaa, Ilukor, John, Hanisch, Markus, Nkonya, Ephraim, Holdsworth, Trevor, Schwabe, Craig A., et al. (2014). Assessing geographical inaccessibility to health care: Using GIS network based methods. Public Health Research, 4(5), 145-159.

15. Anhorn, J., \& Khazai, B. (2015). Open space suitability analysis for emergency shelter after an earthquake. Natural Hazards and Earth System Sciences, 15(4), 789-803.

16. Yoo, H.-H., \& Song, S.-R. (2012). Suitability assessment for flood disaster shelters of Jinju City. Journal of the Korean Society for Geo-Spatial Information System, 20(3), 90-91.

17. Son, S.-R., \& Yoo, H.-H. (2013). Evacuation suitability assessment of shelters in disaster risk districts of Changwon city. Journal of the Korean Society for Geo-Spatial Information System, 21(3), 27-35.

18. Kim, H. S., Kim, M. H., Kim, D. K., \& Ko, S. Y. (2012). An analysis of accesses to major Seoul hospitals/health centers and public transportation improvements for aged medical service 
visitors. Journal of Korea Transportation Research Society, 66(1), 572-657.

19. Lee, J. Y., \& Lee, S. J. (2011). Vulnerability analysis on fire service zone using map overlay method in GIS. Journal of the Korean Society of Surveying Geodesy Photogrammetry and Cartography, 29(1), 91-100.

20. Hwang, J. H., Lee, J. Y., Park, S. W., Lee, D. W., Lee, B. W., \& $\mathrm{Na}$, B. J. (2012). The analysis of underserved emergency medical services areas in Daejeon metropolitan city using a geographic information system. Korean Society for Agricultural Medicine and Community Health, 27(2), 76-83.

21. Shim, W. B. (2013). A study on imroving the methods to analyze urban disaster vulnerability due to climate change. KRISH Issue Paper 2013-1.

22. Ministry of the Interior and Safety. (2016). Cooling center data.

23. Yoo, S. J., Lee, W. K., Oh, S. H., \& Byun, J. Y. (2012). Vulnerability assessment for public health to climate change using spatio-temporal information based on GIS. Spatial Information Research, 20(2), 13-24.

24. Eum, J.-Y., \& Yun, S.-J. (2015). A study on the heatwave management plan for low-income aged people. Korean Association of Space \& Environment Research., 25(4), 317-342.
25. Lee, K. O. (2000). Analysis of children's gait parameters. Korean Journal of Physical Education, 39(2), 527-536.

26. Hong, H.-R., Seo, D.-G., Hasemi, Y., \& Kown, Y.-J. (2011). A study on the walking speed of crowd for safety evacuation design of the elderly. Journal of Korean Institute of Fire Science and Engineer, 25(1), 19-26.

27. Chae, Y.R, Ahn, Y. J., \& Kim, D. S. (2016). Provision of efficiency of heat shelter against warming. KEI Focus, 4(1), 1-28.

28. IPCC. (2007). Summary for policymakers. In: M.L. Parry, O. F. Canziani, J. P. Palutikof, P. J. van der Linden, C. E. Hanson (Eds.) Climate change 2007: Impacts, adaptation and vulnerability. Contribution of working group II to the fourth assessment report of the intergovernmental panel on climate change (pp. 7-22), Cambridge: Cambridge University Press.

29. Fraser, A. M., Chester, M. V., Eisenman, D., Hondula, D. M., Pincetl, S. S., English, P., et al. (2016). Household accessibility to heat refuges: Residential air conditioning, public cooled space, and walkability. Environment and Planning B: Planning and Design, 44(6), 1036-1055. 